\title{
PLATÃO E ROUSSEAU: SOBRE A ALMA DO GOVERNANTE
}

\author{
PLATÃO AND ROUSSEAU: about the the soul of the ruler \\ PLATÃO Y ROUSSEAU: sobre el alma del gobernante
}

\author{
José Assunção Fernandes Leite \\ Professor Doutor da Universidade Federal do Maranhão (UFMA). \\ jfakenaton@uol.com.br
}

RESUMO: O filósofo genebrino Jean-Jacques Rousseau, em suas reflexões políticas, mais precisamente, no primeiro livro Do Contrato Social, ao expor sobre de quem deveria ser a responsabilidade de pensar sobre as formas de governar, argumenta: "Entro na matéria sem demonstrar a importância de meu assunto. Perguntar-me-ão se sou príncipe ou legislador, para escrever sobre política. Se fosse príncipe ou legislador, não perderia meu tempo, dizendo o que deve ser feito; haveria de fazê-lo, ou calar-me". Ora, como não somos nem príncipes e nem governantes, faremos o que fez Jean-Jacques, investigaremos que mérito é esse recebido por alguns homens para que possam governar. Para esta investigação recorreremos a Platão como contra ponto ao filósofo iluminista, ao utilizar-se do conceito de alma e suas potências para legitimar os estamentos de uma cidade justa e o governo do filósofo $n$ 'A República. Para esse confronto utilizaremos o Discurso sobre a origem e os fundamentos da desigualdade entre os homens onde o filósofo faz sua análise das formas de governo e qual seria a melhor delas para os homens viverem e, os discursos empregados como forma de persuadir os demais para aceitarem as formas de governo.

PALAVRAS-CHAVE: Alma. Governante. Mérito pessoal. Discurso.

ABSTRACT: The genevese philosopher Jean-Jacques Rousseau in your politics reflexions, precisely, in the first book Of the Social Contract, to exhibit about whose should be the responsibility of think about the forms of to govern, argue: "I come in the matter without to show the importance of the subject. They will ask me if I am a prince or legislator, to write about politics. If I were prince or legislator, I am not would lost my time, saying what should be done; should I do it or shut up me." Well, how we will do what did Jean-Jacques, we will investigate what merit is this received for some kind of men to can to govern. For it we will recourse to Platão like counterpoint to the illuminist philosopher, when he use the concept of soul and your potency for legitimate the class of a fair city and the government of philosopher in the Republic. For this confront we will use the Speech about the origin and the basis of the inequality among the men where the philosopher make your analyses of the forms of govern and what would be the best of them to the others men live and, the speech used like a way to accept your forms of govern.

KEYWORDS: Soul. Ruling. Personal merit. Speech.

RESUMEN: El filósofo ginebrino Jean-Jacques Rousseau, en sus reflexiones políticas, más precisamente, en el primero libro Del Contrato Social, al exponer sobre de quién debería ser la responsabilidad de pensar sobre las formas de gobierno, argumenta: "Entro en la materia sin demonstrar la importancia de mi asunto. Preguntarán si soy príncipe o legislador, para escribir sobre política. Si fuera un príncipe o legislador no perdería mi tiempo, diciendo lo que debe ser hecho, habría de hacerlo o callarme." Pues, como no somos ni príncipe ni legislador, haremos lo que ha hecho Jean-Jacques Rousseau, investigaremos cuál mérito es ese recibido por algunos hombres para que puedan gobernar. Para esta investigación recurriremos a Platão como contrapunto al filósofo iluminista, al utilizar del concepto de alma y sus potencias para legitimar los estamentos de una ciudad justa y el gobierno del filósofo En la República. Para esa confrontación utilizaremos el Discurso sobre la origen y los fundamentos de las desigualdades entre los hombres donde el filósofo haz su análisis de las formas de gobierno y cuál sería la mejor de ellas para los hombres vivieren y, los discursos empleados como forma de persuadir a los demás para aceptaren las formas de gobierno.

PALABRAS CLAVE: Alma. Gobernante. Mérito personal. Discurso.

Artigo recebido em setembro de 2015

Aprovado em novembro de 2015

Cad. Pes., São Luís, v. 22, n. Especial, set./dez. 2015 
PLATÃO E ROUSSEAU | José Assunção Fernandes Leite

\section{1 | INTRODUÇÃO}

O que chama a atenção nas obras de Jean-Jacques Rousseau é a atualidade das suas reflexões. Há algum tempo que venho me questionando sobre as formas como os nossos legisladores vêm tratando a coisa pública, as suas escabrosas justificativas para os desvios de recursos, os desmandos políticos, a falta de políticas públicas para recuperação dos detentos por delitos etc.. Perguntava-me se existe algo na natureza dos homens que justifique a ambição desenfreada ou suas constantes mentiras para legitimar tais ações. Como também, se perdemos a capacidade de ver e investigar sobre as atitudes dos nossos governantes.

Foram dessas observações que por um lado, lendo Platão, procurei em sua filosofia algo que explicasse a causa das ações excessivas dos governantes. E por outro, lendo a filosofia de Rousseau, compreendi que a construção dos discursos políticos é para justificar e apresentar certos méritos para legitimar e fazer com que o grande público aceite as atividades deles. Isso possibilitou-me fazer uma nova leitura de Platão a partir do pressuposto de Rousseau acerca do conceito do mérito existente nos discursos que constroem as formas de governo.

Parto, para tanto, da seguinte afirmação do genebrino no Contrato (ROUSSEAU, 1996, p. 21):

Entro na matéria sem demonstrar a importância de meu assunto. Perguntar-me-ão se sou príncipe ou legislador, para escrever sobre política. Respondo que não, e que por isso escrevo sobre política. Se fosse príncipe ou legislador, não perderia meu tempo, dizendo o que deve ser feito; haveria de fazê-lo, ou calar-me.

Tendo nascido cidadão de um Estado livre e membro do soberano, embora fraca seja a influência que minha opinião possa ter nos negócios públicos, o direito de neles votar basta para impor o dever de instruir-me a seu respeito, sendo-me feliz todas as vezes que medito sobre os governos, por sempre encontrar, em minhas cogitações, motivos para amar o governo do meu país.

Essa afirmação de Rousseau nos coloca no centro das atividades políticas, uma vez que somos votantes, vivemos em uma República onde escolhemos os legisladores e, portanto, temos o dever de nos instruir a seu respeito, mesmo que seja nas matérias ilícitas realizadas pelo soberano para combatermos esses tipos de ações.

\section{2 | DESENVOLVIMENTO}

Para que possamos nos instruir sobre essa matéria, vejamos como Platão e Rousseau pensam sobre ela. No Discurso sobre a origem da desigualdade ao tratar sobre o governo tirânico, Rousseau (1993) ao se referir a Platão, trata-o como sábio. Isso mostra o apreço e respeito do genebrino pelo grego Platão, mas isso não significa que ele não discorde em alguns momentos do pensamento deste, principalmente quando trata dos fundamentos da origem do governante. Passemos, então, a investigar a ordem política pensada por Platão em sua obra A República, que nos servirá de referência para a compreensão do mérito.

Para encontrar uma forma de demonstrar a justiça plasmada em uma cidade, Platão passa a construir uma em logos. Essa cidade é fundada com base nas necessidades básicas dos homens (369c-d), tais como: alimentação, vestuários e habitação. Nessa cidade criada em logos cada homem executará o seu trabalho próprio em benefício de todos (PLATÃO, 1993).

Para justificar as atividades diferentes que cada um deverá exercer, ele afirma que "cada um de nós não nasceu igual a outro, mas com naturezas diferentes, cada um para a execução de sua tarefa" (PLATÃO, 1993, 370b). Esse argumento vai servir para justificar as diferentes tarefas que cada um devera exercer na cidade, como verificaremos. 
A cidade em seu primeiro momento se organiza para satisfazer as necessidades básicas dando origem ao primeiro estamento ou classe: os artesãos (371a e seguintes). Essa classe é a base de qualquer cidade, ela será responsável por manter o sustento da mesma. Uma cidade muito simples é pensada primeiramente, mas ela não se mantém porque os homens desejam luxo e, portanto, precisará ser expandida. Ao se expandir, aumenta em quantidade de artesãos uma vez que precisará produzir em excesso e luxo, para gerar riquezas. Ao se tornar rica e próspera nada garante a ela que ficará livre dos ataques dos seus vizinhos, como também poderá querer expandir o seu território para aumentar sua produção, isso vai possibilitar o aparecimento de um segundo estamento, os guardiões (374b e seguintes). Essa classe vai se responsabilizar pela segurança da cidade (PLATÃO, 1993).

Manter uma cidade em ordem, de modo que cada um exerça sua função de forma adequada, é necessário para que ela seja educada. $\mathrm{E}$, para essa função, aparece o governante. A ele caberá o papel de legislador e educador de todos. Logo a ele será dado o poder de determinar a função de cada um, de acordo com a potência que cada um demonstrar em seu percurso educativo.

Temos então três classes que serão educadas para realização de apenas uma função específica. Fica agora a seguinte pergunta: qual é o fundamento encontrado por Platão para que cada um exerça apenas uma função e não interfira nas dos outros? Esta explicação encontra-se na sua teoria da constituição da alma e no papel educativo da pólis.

Logo no Livro I de A República, ao expor o diálogo retórico entre Sócrates e o sofista Trasímaco, que trata do problema apresentado pelo sofista, de que a justiça ${ }^{2}$ é um vicio e a injustiça uma virtude, invertendo assim a ordem do entendimento das duas, Sócrates, para desmontar o argumento erístico do seu adversário, passa a verificar a areté de cada coisa e entre elas a alma (PLATÃO, 1993).

Na passagem 353d, ele afirma que:

\begin{abstract}
Ora, vamos lá, depois disto, a examinar este ponto. A alma tem uma função, que não pode ser desempenhada por toda e qualquer outra coisa que exista, que é a seguinte: superintender, governar, deliberar e todos os demais atos da mesma espécie. Será justo atribuir essas funções a qualquer outra coisa que não seja a alma, ou deveremos dizer que são específicas dela. (PLATÃO, 1993).
\end{abstract}

A alma aparece nesse primeiro momento, no diálogo, enquanto uma unidade que coordena as atividades que necessitam de deliberação do ser humano e, portanto, possui uma função muito própria, tal qual a justiça, por isso não se pode inverter a ordem das coisas como planejou Trasímaco. Ela, a alma, é a causa motora que anima o corpo e, portanto a causa da vida. Logo, todos os homens são por natureza dotados dela.

Mas se somos dotados de alma e de corpo, o que nos faz diferentes uns dos outros? Rousseau (1983, p. 235) logo no início do Discurso sobre a origem e os fundamentos da desigualdade entre os homens, ao expor que vai examinar o homem, explica que:

Concebo na espécie humana, dois tipos de desigualdades: uma que chamo de natural ou
física, por ser estabelecida pela natureza e que consiste na diferença das idades, da saúde,
das forças do corpo e das qualidades do espírito e da alma: a outra, que se pode chamar
de desigualdade moral ou política, porque depende de uma espécie de convenção e que
é estabelecida ou, pelo menos, autorizada pelo consentimento dos homens. Esta consiste
nos vários privilégios de que gozam alguns em prejuízo de outros, como o serem mais ricos,
mais poderosos e homenageados do que estes, ou ainda por fazerem-se obedecer por eles.

${ }^{1}$ Para compreender melhor a origem da alma ver: Platão (2000), Gazolla (1993), Robinson (2007).

2 Sobre a noção de justiça ver: Maffetone e Veca (2005). 


\section{PLATÃO E ROUSSEAU | José Assunção Fernandes Leite}

Vamos então nos deter na primeira diferença apontada pelo genebrino, a da alma. Se o referido filósofo tem como referência de suas reflexões a história e ela registra todos os movimentos da alma humana, nela se pode perceber os homens vivendo em grupos, mas a natureza deixando sua marca em cada um enquanto modo de se expressar na sua individualidade. Uns mais lentos na atividade de pensar, outros mais astuciosos, uns mais criativos, outros sem iniciativas e assim se percebe a diferença apontada por Jean-Jacques.

Quanto ao grego Platão ao expor sobre a noção de alma enquanto uma força ou potência que anima a vida, vai ter de explicar onde se encontra essa diferença que não seja fundada na história, mas na própria physis da alma. Como já exposto, Rousseau toma como referência a história para observar e justificar as diferenças e Platão se fundamenta em uma metafísica para justificar as diferentes funções que cada um deverá exercer na cidade.

No Livro IV, de A República, ao tratar das excelências existentes na cidade: a temperança, a coragem, a sabedoria e a justiça, Platão (1993) precisa localizá-las também na alma e passa a verificar em quantas partes ela se constitui. Na passagem 349d ele expõe:

Não é, portanto, sem razão que consideraremos que são dois elementos, distintos um do
outro, chamando àquele pelo qual ela raciocina, o elemento racional da alma, e aquele
pelo qual ama, tem fome e sede e esvoaça em volta de outros desejos, o elemento irra-
cional e da concupiscência, companheiro de certas satisfações e desejos [...] Por con-
seguinte - prossegui eu - vamos distinguir na alma a presença destes dois elementos.
Porém o da ira, pelo qual nos irritamos, será o terceiro [...].

Pelo exposto, o grego já tinha anunciado que por natureza somos diferentes e que essa diferença se encontra na natureza da alma de cada um e uma cidade que pretenda ter uma bela constituição deverá seguir a ordem da alma. Por isso a necessidade dos estamentos na cidade, para neles se desenvolver as potencias já existentes na alma.

$\mathrm{Na}$ classe dos artesãos se encontra a concupiscência, na qual os desejos serão direcionados para a produção das riquezas e manutenção da vida. No segundo estamento encontramos a classe dos guardiões, sede da epitímia, da ira direcionada para a proteção da cidade e para a guerra, quando for necessária. E por fim o terceiro estamento, a do governante, sede da razão, do lógos direcionado ao governo e educação da cidade.

Todo esse processo passa por uma aceitação dos habitantes da cidade, o lógos deverá persuadir que essa nova forma de governo é a melhor para todos e para isso, faz-se necessário livrar-se dos habitantes que já tenham em suas almas impregnações de outros modelos considerados viciosos, segundo Platão (1993), e uma nova geração construirá a nova cidade.

O projeto da consolidação da cidade justa passa pelo processo de modelamento do cidadão com a finalidade de exercer a sua função específica e, ao mesmo tempo, ter o cuidado com o sentimento que deverá ser cultivado em cada um. Por esse motivo, a educação é de responsabilidade da cidade, o governante precisa saber o que deverá ser ensinado a cada um, em cada faixa etária e de acordo com a sua função. Todos receberão um mito comum como forma de entendimento de suas origens e desenvolvimento do laço da philia. Para isso, contar-se-á às crianças o mito das raças hesiódico, que é exposto da seguinte forma:

[...] na verdade, tinham sido moldados e criados no interior da terra, tanto eles, como as suas armas e o restante equipamento; e que, depois de eles estarem completamente forjados, a terra, como sua mãe que era, os deu à luz, e que agora devem cuidar do lugar

\footnotetext{
${ }^{3}$ Sobre a história como registro do homem ver: Starobinski (2011).
} 


\begin{abstract}
em que se encontram como de uma mãe e ama, e defendê-la, se alguém for contra ela, e considerar os outros cidadãos como irmão, nascidos da terra [...]. Vós sois efetivamente todos irmãos nesta cidade...mas o deus que vos modelou àqueles dentre vós que eram aptos para governar, misturou-lhes ouro na sua composição, motivo por que são mais preciosos; aos auxiliares, prata; ferro e bronze aos lavradores e demais artífices. Uma vez que sois todos parentes na maior parte dos casos gerareis filhos semelhantes a vós, mas pode acontecer que de ouro nasça uma prole argêntea, e da prata, uma área, e assim todos os restantes, uns dos outros. (PLATÃO, 1993 [414d - 415a-c]).
\end{abstract}

Observa-se, pelo exposto, o fundamento da organização da cidade, esse mito deverá ser internalizado ou como afirma Platão, plantado na alma de cada um para que possa aceitar as diferenças existentes nas funções a serem exercidas por todos na cidade. Nesse mito, observa-se, também, o fundamento da desigualdade e dos méritos que estarão presentes nas funções que cada um exercerá na polis justa. Mas todos possuem em comum uma origem e as potencias não dependem dos homens, mas dos deuses que são responsáveis por modelarem a alma humana.

Essa ideia de origem comum possibilitará entre os homens a aceitação das diferenças existentes entre eles, uma vez que o laço de irmandade deve ser muito mais forte do que tais diferenças.

É na alma que se encontram as potencias para as funções da artesania, do guerreiro e do governante. Essa é uma sociedade que organiza aquilo que já é por natureza: as almas são o que são pelas mãos dos divinos deuses. Logo, aos homens questionar aquilo que é estabelecido pela natureza não faz sentido, mas sim seguir o seu fluxo, para isso observam-se as diferenças e se adequa cada um em sua devida função, para o seu bem e o bem da cidade.

Dadas as devidas explicações de Platão para a construção de uma aristocracia fundada em méritos recebidos pela natureza ou porque não dizer, do divino filósofo, vejamos a compreensão do genebrino, seguindo, assim, sua própria indicação, já que, como cidadãos da polis, devemos nos instruir sobre as diferenças.

No seu Discurso sobre a origem e os fundamentos da desigualdade entre os homens, Rousseau (1983) expõe como os homens, no percurso da história, vão despertando e desenvolvendo suas faculdades e aprendendo a tirar proveito delas. No primeiro momento da vida, o homem desperta para o sentimento da sua existência e com esse sentimento vem o cuidado com a sua conservação.

Dessa condição, o homem passa a lidar com as diversidades da natureza que naturalmente vai engendrando no seu espírito a percepção de outras relações. Passa então, a ter observações simples, maquinal das coisas, tais como: grande, pequeno, forte, fraco, depressa, devagar, medroso, ousado e ideias similares. Com o tempo foram desenvolvidas a faculdade da memória e a imaginação, o amor-próprio interessado e a razão ativa em sua quase perfeição.

Mas, nesse desenvolvimento, foi preciso para a vantagem própria de alguns, mostrar-se diferente daquilo que se é de fato. Então, aparece um dos problemas cruciais dos homens: ser e parecer. É nessa distinção entre o ser e o parecer que, para Rousseau (1983), surgiram o fausto imponente, a astúcia enganadora e todos os vícios que constituem o seu cortejo.

Entre tantas astúcias enganadoras dos homens, ele expõe sobre uma das primeiras delas: a propriedade. Como argumenta o filósofo:

O primeiro que, tendo cercado um terreno, se lembrou de dizer: Isto é meu, e encontrou pessoas bastante simples para o acreditar, foi o verdadeiro fundador da sociedade civil. Quantos crimes, guerras, assassínios, misérias e horrores não teria poupado ao gênero humano aquele que, arrancando as estacas ou tampando os buracos, tivesse gritado aos seus semelhantes. "Livrai-vos de escutar esse impostor; estarei perdidos se esquecerdes que os frutos são para todos, e a terra de ninguém!". Parece, porém, que as coisas já tinham chegado ao ponto de não mais poder ficar como estavam: porque essa ideia de propriedade, dependendo muito de ideias anteriores que só puderam nascer sucessivamente, não se formou de repente no espírito humano: foi preciso fazer muitos progressos, adquirir 
muita industria e luzes, transmiti-las e aumentá-las de idade, antes de chegar a esse último termo do estado da natureza. Retornemos, pois, as coisas de mais alto, e tratemos de reunir, sob um só ponto-de-vista, essa lenta sucessão de acontecimentos e de conhecimentos na sua ordem natural. (ROUSSEAU, 1983, p. 91).

Pelo exposto, algumas diferenças são frutos da astúcia humana, de ir convencendo uns aos outros, de tal modo que se possa usufruir dos benefícios retirados dos mais fracos. Esse processo, como afirmou Rousseau (1983), depende do tempo e é registrado na história da evolução dos homens. É um progresso da própria faculdade do homem que se despertou e foi se articulando. Logo o que se tem no homem nada mais é do que o resultado do aperfeiçoamento de sua natureza. E certas diferenças quando acentuadas entre os homens são resultado de algo que já vinha sendo cultivado anteriormente.

Voltando a Platão (1993), que nos informa que por natureza temos uma alma que é comum a todos e, que tem como areté a função de superintender, governar, deliberar e todos os demais atos da mesma espécie, vejamos que mérito é esse que impossibilitaria o artesão de governar.

Se para exercer a sua artesania, o artesão não pode ser alguém que usa exclusivamente só e somente só, a sua potência epitimética, ele necessitará das outras potências: timocrática e logística. Logo, o desejo básico desse homem está atrelado à satisfação das coisas básicas e acúmulo de bens, mas para isso, ele necessita da coragem para mover-se, para concretizar os seus objetivos. E por fim, o logos será o seu companheiro para ir dando medida e proporção aos seus feitos, já que ele vai produzir e para produzir algo, sabe-se que são necessárias noções básicas de medida e proporção. E essas noções são dadas pelo logos.

Então, se um homem que sabe ter medida e proporção dos seus feitos e sabe que isso pode ser transposto para sua relação com os outros possibilitando uma convivência equilibrada, por que ele não pode governar? Por que o mérito deve ser do filósofo? Só por ser aquele que possui a larga visão? Mas, devemos lembrar que ele, o filósofo, também possui as outras potências e nada garante que ele não entre em desmedida no próprio logos. Tanto pode entrar em desmedida que Platão nos livros VIII e IX vai ter de tratar das outras formas de governo. E essas mudanças se dão devido às próprias desmedidas na alma.

Sendo assim, temos de concordar com o sofista Trasímaco, que afirma ser a justiça a conveniência do mais forte (Rep. 338c) e esse mais forte, ao qual ele se refere, é o governo. Portanto sendo o governo o mais forte, vai legislar em benefício do mais forte, logo legislar em benefício próprio e não, como pensa Platão, governar em benefício dos mais fracos. Essa parece ser exatamente a experiência histórica dos gregos e que Platão parece não querer aceitar, mas procura puxar o poder para uma aristocracia que não seja mais fundada nos laços familiares, porém nas potencias da alma. E cria, portanto, novos méritos baseados em tais potencias.

Conforme Rousseau (1983), esses méritos são resultados das percepções que os homens articularam com suas vivências na natureza e não algo metafísico. Algumas diferenças são resultado da natureza, ser mais alto, mais baixo, mais forte e mais fraco. Observando uns mais fortes, outros mais fracos, constrói-se um governo baseado em méritos e não na deliberação baseada na vontade geral, que primeiro pensa na preservação do conjunto, ao invés de proveitos particulares e, dessa forma, criam-se dificuldades, através da construção de méritos, para que não se possa pensar sobre a forma como se está legislando.

Resguardadas as devidas distâncias e diferenças essa prática parece ainda ecoar no presente contexto, haja vista prevalecer a ideia de que se não sou um político não penso nas coisas públicas. Essa é uma das capacidades que o governo parece querer apagar do cidadão: a capacidade de pensar sobre a sua forma de legislar. Ao negar educação e condições básicas para todos, o governo possibilita exatamente isso, a incapacidade de pensar sobre as suas ações. 
PLATÃO E ROUSSEAU | José Assunção Fernandes Leite

\title{
3 | CONSIDERAÇÕES FINAIS
}

Resta-nos, portanto, buscar saber quando nos daremos a oportunidade de pensar sobre a ação política. Esse é um problema que só nos diz respeito quando somos em uma grande maioria atingidos pela ação do governo. Nesse caso observamos uma parte se movendo e outra em inércia por não entender o que acontece.

Mas o que impossibilita os homens se moverem contra certas atitudes dos governantes? De certo, porque já foram persuadidos de que a coisa pública e seus direcionamentos são de responsabilidade dos políticos e não do cidadão da pólis. Então, o que aconteceu para termos chegado aonde chegamos?

Nesse caso, volto ao genebrino no segundo Discurso (ROUSSEAU, 1983), a fim de lembrar que este, ao retomar a imagem do filósofo grego Diógenes, que procurava com a sua lanterna pelo homem, nos afirma que o referido filósofo procurava por um homem natural fora do seu tempo, sendo que o homem natural não existia mais. $E$ hoje quando nós procuramos pelo homem, encontramos o quê?

Pelo exposto, as artimanhas dos próprios homens foram construindo algo de novo, a aparência, o que deve aparecer e não mais o que deve ser. Nesse contexto de parecer ser, ao que tudo indica foi jogada na alma humana certa quantidade de água do rio Lettes e fomos esquecendo o que somos. Então o que encontramos? Para essa resposta vamos nos utilizar do mito platônico da estátua de Glauco retomado por Rousseau (1983, p. 138), escrito da seguinte forma:

\begin{abstract}
Semelhante à estatua de Glauco que o tempo, o mar e as tempestades haviam desfigurado tanto que se parecia menos com um deus do que com um animal feroz, a alma humana alterada no seio da sociedade por mil causas continuamente renascentes, pelas aquisições de uma multidão de conhecimentos e de erros, pelas mudanças ocorridas na constituição dos corpos, e pelo choque contínuo das paixões, por assim dizer mudou de aparência a ponto de ser irreconhecível.
\end{abstract}

Se para o seu tempo Platão já via o homem desfigurado pelas paixões e desejos e Rousseau só constata, no século XVIII, com mais evidência o problema, chegando ao século XXI no qual ficamos perdidos nas paixões do parecer ser prósperos e equipados de todas as tecnologias $e$ em uma sociedade fabricadora de desejos sem fim para um consumo sem limites. Quando nos procuramos, realmente nos encontramos desfigurados como a estátua de Glauco, bem como tudo o que fazemos, tudo que produzimos, inclusive o próprio governo, acha-se igualmente desfigurado, pois ele nada mais é do que o reflexo dos seus habitantes.

${ }^{4}$ Sobre o deus Glauco ver: Starobinski (2011). 
PLATÃO E ROUSSEAU | José Assunção Fernandes Leite

\section{Referências}

GAZOLLA, R. Platão: o cosmo, o homem e a cidade. Petrópolis: Vozes, 1993.

MAFFETTONE, S.; VECA, S. A ideia de justiça de Platão a Rawls. Tradução Karina Jannini. São Paulo: Martins Fontes, 2005.

PLATÃO. A República. Tradução M. H. Pereira. Lisboa: Calouste Gulbenkian, 1993.

Timeu. Tradução Calos Alberto Nunes.

Belém: RFPA, 2000.

ROBINSON, T. M. A psicologia de Platão. Tradução Marcelo Marques. São Paulo: Ed. Loyola, 2007.
ROUSSEAU, J.-J. Discurso sobre a origem e os fundamentos da desigualdade entre os homens. Tradução Lourdes Santos Machado. 3. ed. São Paulo: Abril Cultural, 1983.

. O contrato social. Tradução Antonio de Pádua Danesi. 3. ed. São Paulo: Martins Fontes, 1996.

STAROBINSKI, J. Jean-Jacques Rousseau: a transparência e o obstáculo. Tradução Maria Lucia Machado. São Paulo: Companhia das Letras, 2011. 